\title{
MODELLING MULTI-DECADAL SHORELINE VARIABILITY AND EVOLUTION
}

\author{
Melissa A. Mole ${ }^{1}$, Mark A. Davidson², Ian L. Turner ${ }^{1}$, Kristen D. Splinter ${ }^{1}$, \\ Ian D. Goodwin ${ }^{3}$ and Andrew D. Short ${ }^{4}$
}

\begin{abstract}
A robust and practical methodology for predicting future shoreline behaviour along sandy coastlines would be valuable to a broad range of coastal engineering applications. Present approaches for predicting shoreline evolution range from simple linear trend models, which cannot predict observed complex behaviour, to coupled hydrodynamic / sediment transport models, with seasonal to multi-year forecasting generally beyond present model capabilities. In this work a simple empirical shoreline variability model, ShoreFor (Shoreline Forecast), is investigated using a multidecadal dataset to assess model performance at daily to decadal timescales. Model performance is assessed at five alongshore locations within an embayed study site that experience varying exposure to the offshore wave climate due to prominent adjacent headlands and display alongshore variable behaviour. To determine model sensitivity to input wave conditions, both the measured offshore and transformed (modelled) nearshore wave data are used and results compared. Strengths and limitations of the ShoreFor model are identified and discussed, along with ongoing model development and planned application of this modelling technique for shoreline forecasting using future water level and wave climate scenarios.
\end{abstract}

Keywords: shoreline evolution; predictive model; equilibrium model; cross-shore sediment transport; embayed beach processes

\section{OVERVIEW}

Amid uncertainty regarding future climate change and the potential impacts on coastal systems and settlements, a robust and practical methodology for predicting weekly up to decadal-scale shoreline variability and change along sandy coastlines would be highly valuable. At the present time there are several predictive tools in use, ranging from linear shoreline regression analyses, to coupled hydrodynamic/sediment transport numerical schemes that attempt to include many of the key physical processes shaping the coastline. The former approach is typically based on sporadic past observations, assuming that the dominant trend in the past is representative of the system and will continue into the future. For this reason, it cannot be used to forecast future variability and change that may include changing sea levels and/or non-stationary regional wave climates. In contrast, numerical process-based models do incorporate the key physical forcing mechanisms and controls on beach behaviour, however, at the present time they tend to be site-specific and require extensive local datasets for calibration, with seasonal to multi-year forecasting beyond present model capabilities.

In this work an empirical shoreline modelling approach is investigated that improves on the generic linear trend approach by incorporating an essential time-varying component that reflects several key physical processes, while maintaining a simple enough formulation to be driven with limited data. The cross-shore movement of the shoreline is controlled by rapidly varying (hourly) incident wave power and the more slowly adjusting equilibrium state of the beach, which is strongly influenced by the antecedent morphology. Conceptually, these core ideas are based on the equilibrium beach state prediction model of Wright et al. (1985).

This present work, which hindcasts shoreline variability over multiple decades, builds on several recent advances in the field of storm to seasonal timescale shoreline prediction due to predominantly cross-shore sediment transport processes (Miller and Dean, 2004; Yates et al., 2009; Davidson et al., 2010; Mole et al., 2011). Based on multi-year datasets from sandy beaches on both sides of the Pacific Ocean, these studies have demonstrated the practical application of this type of empirical modelling approach to both hindcasting and forecasting shoreline variability for simulation lengths up to several years. The aim of this new work is to investigate the performance of an empirical shoreline forecasting model, ShoreFor (Shoreline Forecast; Davidson et al., submitted) which refines and extends these previous works. In this study, an unbroken 22 year monthly shoreline time-series from NarrabeenCollaroy, NSW, Australia, and concurrent wave data is used to test the model's ability to reproduce the complex and variable seasonal to multi-year behaviour observed at this site.

\footnotetext{
${ }^{1}$ Water Research Laboratory, School of Civil and Environmental Engineering, University of New South Wales, 110 King St, Manly Vale, NSW 2093, Australia

${ }^{2}$ School of Marine Science and Engineering, University of Plymouth, Drake Circus, Plymouth, Devon PL4 8AA, UK

${ }^{3}$ Marine Climate Risk Group, Environmental Science, Macquarie University, Sydney, Australia

${ }^{4}$ CoastalCOMS, Varsity Lakes, QLD, Australia
} 


\section{STUDY SITE}

This investigation draws on the extensive shoreline dataset available from the South-East Australian Climate Change Coastal Reference Station (SEA-CCCRS) based in the Narrabeen-Collaroy, NSW embayment, henceforth referred to as Narrabeen. At this site, monthly cross-shore profiles have been measured at five locations spanning the $3.6 \mathrm{~km}$ long embayment since 1976 (see Fig. 1 and Harley et al., 2011a, for a comprehensive discussion of the monitoring program, including measurement techniques and uncertainties). In this study, the terms "beach width" and "shoreline position" refer to the cross-shore position of the mean sea level contour relative to a fixed landward bench mark.

The Sydney region is characterized as wave dominated, with mean significant wave height of $1.6 \mathrm{~m}$ and peak period of $10 \mathrm{~s}$, and is microtidal with spring tidal range less than $2 \mathrm{~m}$. Measured wave data is available from a wave buoy located in $80 \mathrm{~m}$ water depth off the southern end of the study site (as indicated in Fig. 1). A non-directional buoy was in place at this location from 1987 to 2000 and a directional buoy since 1992. The analysis presented in this work is limited to the 1987-2011 when concurrent beach widths and measured wave data are available.

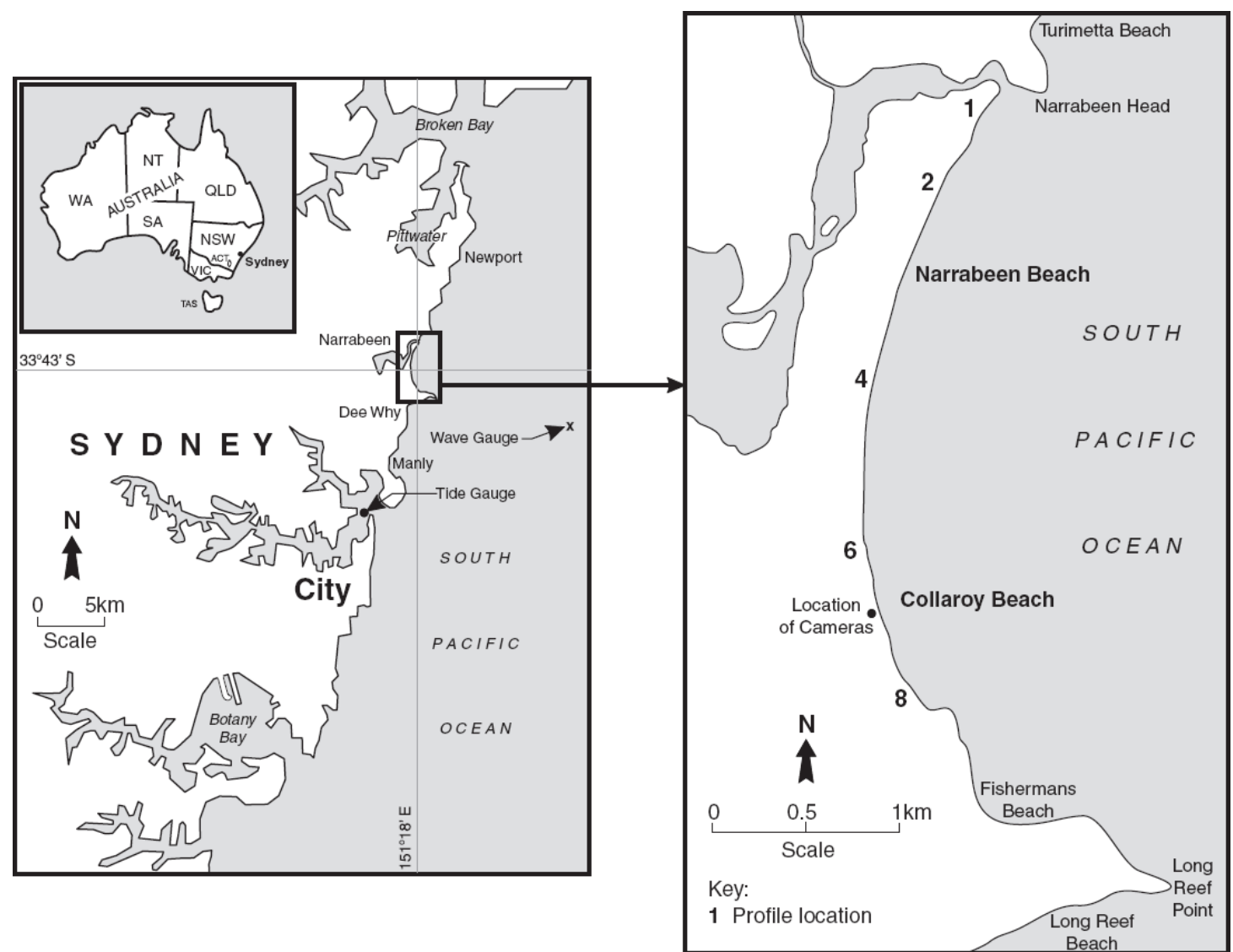

Figure 1. Location of the Narrabeen-Collaroy embayment on the south-east Australian Coastline. The alongshore locations of the measured profiles are indicated as 1, 2, 4, 6 and 8 (source: Harley et al., 2011a).

The multi-decadal beach width timeseries derived from the five cross-shore profiles measured at Narrabeen exhibit both common and contrasting behaviour as shown in Figure 2. Rapid erosion is observed across all profiles during large storm events (e.g. 1978, 1995 and 2007) and contrasting behaviour is evident at longer timescales, where multi-year accretion-erosion events occur at different times at different alongshore locations (e.g. Profile 8 between 1978 and 1989; Profile 1 between 1989 and 2000). These non-uniform shoreline displacements have been attributed to a combination of crossshore and alongshore sediment transport processes, with recent work finding that in the order of $60 \%$ of the variability over the 35 year record may be attributed to cross-shore sediment transport (Harley et al., 2011b) making this an appropriate target for a purely cross-shore model like ShoreFor to reproduce.

While the range of observed cross-shore shoreline positions is up to $80 \mathrm{~m}$ (standard deviation up to $15 \mathrm{~m}$ ), the record mean trends are generally negligible (in the order of a few centimetres per year; see Table 1). Thus it is apparent that the Narrabeen embayment is in a state of dynamic equilibrium with the 
long term average wave climate and water level, as the mean cross-shore shoreline position is relatively stable during the observed decades. In the results presented in this study, the shoreline timeseries is restricted to either 1987-2011 when offshore non-directional wave data is available, or 1992-2011 when offshore directional wave data is available. It is noted that the linear trends observed over these shorter timescales differ from the record mean values as indicated in Table 1 and thus should not be considered representative of the longer term behaviour of this site.

\begin{tabular}{|c|c|c|c|}
\hline & $1976-2011$ & $1987-2011$ & $1992-2011$ \\
\hline Profile 1 & 0.05 & -0.73 & -1.82 \\
\hline Profile 2 & 0.10 & -0.35 & -1.01 \\
\hline Profile 4 & -0.56 & -0.72 & -0.77 \\
\hline Profile 6 & 0.16 & 0.20 & 0.35 \\
\hline Profile 8 & -0.11 & 0.34 & 0.74 \\
\hline
\end{tabular}
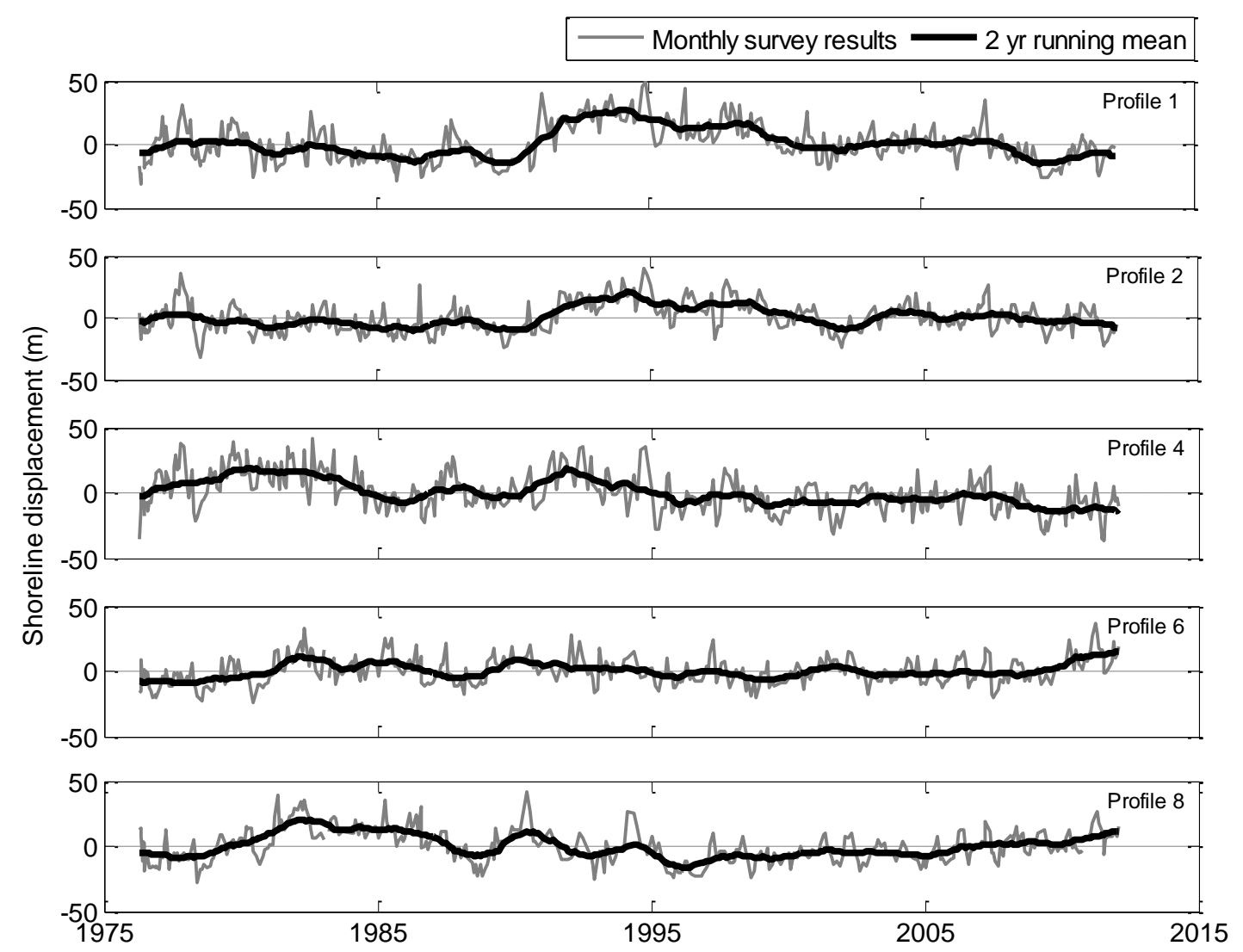

Figure 2. Multi-decadal record of beach width at five alongshore locations within the Narrabeen embayment.

\section{MODEL FORMULATION}

Davidson et al. (submitted) recently proposed the formulation of a new empirical shoreline variability model, ShoreFor, within which cross-shore shoreline displacement is controlled by incident wave power; instantaneous disequilibrium relative to the more slowly adjusting beach state; and calibrated accretion-erosion response rates. Conceptually this model approach is adopted to replicate observed shoreline behaviour during periods of storm and recovery:

1. Little change on an accreted beach in response to sustained low energy and low steepness waves (low wave power and small disequilibrium).

2. Rapid erosion of an accreted beach in response to steep and energetic waves (high wave power and large disequilibrium).

3. Slowed erosion response of eroded beach under sustained steep and energetic waves (high wave power but small disequilibrium). 
4. Rapid but small initial recovery of eroded beach in response to smaller, less steep waves (low wave power but large disequilibrium).

5. Slower sustained recovery of eroded beach in response to sustained smaller, less steep waves (low wave power and small disequilibrium).

In the ShoreFor model, the rate of change of the cross-shore shoreline coordinate $x$ as a function of time $t$ is given by:

$$
\frac{\mathrm{dx}}{\mathrm{dt}}=\mathrm{b}+\mathrm{c}^{ \pm} \mathrm{P}(\mathrm{t})^{0.5}\left(\Omega_{\mathrm{eq}}(\mathrm{t})-\Omega(\mathrm{t})\right)
$$

where: $P$ is deepwater wave power $(\mathrm{W} / \mathrm{m}) ; \Omega$ is dimensionless fall velocity as defined in Eq. 2 (after Gourlay, 1968 and Dean, 1973); and $\Omega_{e q}$ describes the equilibrium dimensionless fall velocity as defined in Eq. 3; $c$ is indicative of the accretion $(c+)$ or erosion $(c-)$ response rate $\left((\mathrm{m} / \mathrm{s}) *(\mathrm{~W} / \mathrm{m})^{-0.5}\right)$; and $b$ is a linear trend term $(\mathrm{m} / \mathrm{s})$ independent of wave forcing to account for otherwise neglected processes (e.g. alongshore sediment transport). Based on the computational simplicity of the model formulation, an iterative method is used to solve for the optimal model coefficients. The accretion and erosion response rates are incorporated such that at time steps where the disequilibrium term $\left(\Omega_{e q}-\Omega\right)$ is positive, accretion is predicted and the $c+$ coefficient is applied and where the disequilibrium term is negative, erosion is predicted and the $c$ - coefficient is applied. Dimensionless fall velocity is incorporated as:

$$
\Omega(t)=\frac{H_{s}(t)}{w_{s} T_{p}(t)}
$$

where: $H_{s}$ is deepwater significant wave height $(\mathrm{m}) ; T_{p}$ is peak period (s); and $w_{s}$ is sediment fall velocity $(\mathrm{m} / \mathrm{s})$. This parameter incorporates both the forcing conditions, as wave height and period, as well as site-specific sediment characteristics via the sediment fall velocity. By this approach, sediment grain size and density are intrinsic to the model, thus increasing the potential for transportability between sites and wider generic applicability.

A key feature of the ShoreFor model is the definition of the equilibrium condition that influences both the direction and rate of cross-shore shoreline movement. In earlier model developments the equilibrium dimensionless fall velocity was defined as the record mean value (Davidson et al., 2010). Based on this definition, shoreline hindcasting at a seasonal timescale was achieved at one study site but was found inadequate at storm to seasonal timescales at another site (Mole et al., 2011). This prompted redevelopment of the model to incorporate the time-varying equilibrium condition used here, which is a weighted product of the antecedent wave conditions (after Wright et al., 1985) given by:

$$
\Omega_{e q}(t)=\frac{\sum_{i=1}^{D} \Omega_{i} 10^{-\phi i}}{\sum_{i=1}^{D} 10^{-\phi i}}
$$

where: $\Omega_{\mathrm{i}}$ is the instantaneous (calculated hourly) dimensionless fall velocity; $D$ is the number of preceding days which are used in the calculation; $\phi$ represents the rate of "memory decay" (Wright $e t$ $a l ., 1985)$ of the system such that the weighting decreases to $10 \%$ at $\phi$ days prior and decreases to $1 \%$ at $2 \phi$ days prior. In this work, $\phi$ values between 5 and 380 days were tested and the optimal value of D $=2 \phi$ was adopted. Thus a lead time of 760 days (approximately two years) of wave data was required at the start of each simulation to ensure that the antecedent conditions were captured fully. Conceptually, this equilibrium condition reflects the underlying, more slowly varying beach state and thus at a fundamental level incorporates morphodynamic feedback. This feedback is essential to calculating the appropriate rate and direction of shoreline change at each timestep, as the same waves can have a distinctly different impact depending on the antecedent beach state and width.

A similar model formulation has been proposed by Yates et al. (2009), which builds on the work by Miller and Dean (2004), however, the ShoreFor model differs from that model in several ways. Most significantly, in the ShoreFor model the equilibrium condition and thus morphodynamic feedback are incorporated implicitly via the time varying wave steepness; rather than explicitly, as in the Yates model, where equilibrium energy is expressed as a function of beach width with no regard for antecedent beach state. This difference may have important implications for modelling future shoreline evolution, as the ShoreFor model has the capability to adjust to shoreline change beyond previously 
observed conditions. The equilibrium condition within the ShoreFor model can evolve with a dynamically changing wave climate without recalibration and thus may provide the capability to forecast beach variability subject to potential future non-stationary wave climates.

\section{SUMMARY OF RESULTS}

This investigation of ShoreFor with multi-decadal time series builds on recent work with six years of weekly beach widths, from two contrasting sandy beaches on the Australian East Coast (Davidson et al., submitted). In this new work, simulations are extended to the 22 year timeseries when measured wave data is available, after the initial two years required to fully characterise the antecedent conditions as described in Eq. 3. Model performance at the five profile locations over this time period is summarised in Table 2 and shown graphically in Figure 3.

\begin{tabular}{|c|c|c|c|c|c|c|c|c|c|}
\hline$\frac{0}{\frac{0}{\bar{N}}}$ & $\begin{array}{l}\Phi \\
\text { (da } \\
\text { ys) }\end{array}$ & $\begin{array}{l}\mathrm{b} \\
(\mathrm{m} / \mathrm{yr})\end{array}$ & $\begin{array}{l}\mathrm{C}+ \\
\left(\mathrm{x} 10^{-8}(\mathrm{~m} / \mathrm{s})^{*}\right. \\
\left.(\mathrm{W} / \mathrm{m})^{-0.5}\right)\end{array}$ & $\begin{array}{l}\text { Ratio } \\
\text { of } \\
\text { C+ to c- }\end{array}$ & $\begin{array}{l}\mathrm{R}^{2} \\
\text { linear } \\
\text { model }\end{array}$ & $\begin{array}{l}\mathrm{R}^{2} \\
\text { ShoreFor } \\
\text { model }\end{array}$ & $\begin{array}{l}\text { RMSE } \\
\text { linear } \\
\text { model } \\
(\mathrm{m})\end{array}$ & $\begin{array}{l}\text { RMSE } \\
\text { ShoreFor } \\
\text { model } \\
(\mathrm{m})\end{array}$ & $\mathrm{BSS}^{1}$ \\
\hline 1 & 220 & -1.06 & 3.36 & 2.17 & $0.53^{2}$ & $0.72^{2}$ & 13.0 & 10.6 & 0.47 \\
\hline 2 & 180 & -0.38 & 2.86 & 2.17 & 0.11 & 0.49 & 11.3 & 8.5 & 0.58 \\
\hline 4 & 180 & -0.70 & 1.49 & 2.16 & 0.15 & 0.23 & 12.7 & 12.1 & 0.26 \\
\hline 6 & 10 & 0.20 & 1.58 & 1.88 & 0.01 & 0.10 & 9.6 & 9.2 & 0.30 \\
\hline 8 & 10 & 0.40 & 1.30 & 1.86 & 0.04 & 0.09 & 10.6 & 10.3 & 0.24 \\
\hline
\end{tabular}

Notes:

1. BSS: The Brier Skills Score is used here to quantify the relative improvement of the ShoreFor model over the linear model. The standard qualitative rankings are: $<0=$ Bad; $0-0.3=$ Poor; $0.3-0.6=$ Fair; $0.6-0.8=$ Good; $0.8-1.0$ = Excellent (see e.g. Sutherland et al., 2004).

2. The skill of the linear trend is unusually high in this simulation (and likewise the skill of ShoreFor is increased) based on the section of the shoreline record modelled here. From Figure 2, if this trend were extrapolated to the start of the record, it would induce a significant error.

Model skill at the northern profiles 1 and 2 is comparable to the approximately $60 \%$ of total variability which has been attributed to cross-shore sediment transport at this site (Harley et al., 2011b). At these profiles, the optimized "memory decay" $(\phi)$ value is around six months, probably reflecting the influence of the large, low frequency variability evident throughout the record, while the rapid storm responses are not as well captured. At the southern profiles, the optimized $\phi$ value is much smaller at just 10 days, making the model more sensitive to storms, but with their effects reducing soon after each event. While the values of the accretion and erosion response rates ( $c+$ and $c-$ ) vary between the profiles, they generally decrease from north (more exposed) to south (less exposed). If the shoreline variability was well represented at all profiles, this would indicate that the north is more responsive to the incident wave climate, however at the present time the reduced coefficients reflect the model approaching the linear trend as low frequency variability is not well represented at the southern profiles. The ratio of $\mathrm{c}+$ to $\mathrm{c}-$ at all profiles is consistently around $2: 1$. This difference in accretion versus erosion rates correctly reflects the observation that accretion must balance erosion for long term stability, but beach recovery occurs during periods of less steep and less powerful waves.

As shown in Figure 3 and Table 2, ShoreFor is an improvement on the linear model at all profiles as indicated by increased correlation, reduced RMSE and positive BSS. It is most successful at the northern profiles 1 and 2, which are more exposed to the modal south-south-easterly wave climate at the study site, and previously shown to be dominated by cross-shore processes (Harley et al., 2011b). At these profiles the model captures storm, seasonal and multi-year accretion/erosion events, although the magnitude of this variability is under predicted and there are visible discrepancies at certain times. Some discrepancies observed may be due to physical processes presently not included in this simple model, such as: extreme water levels; impacts of varying wave direction (and hence different degrees of sheltering by the adjacent headlands); alongshore sediment transport; sediment sinks or sources, such as the nearby estuary entrance; or localised morphological features such as rip embayments or welded sandbars, both of which occur frequently at the study site (Short, 1985). 
6

COASTAL ENGINEERING 2012
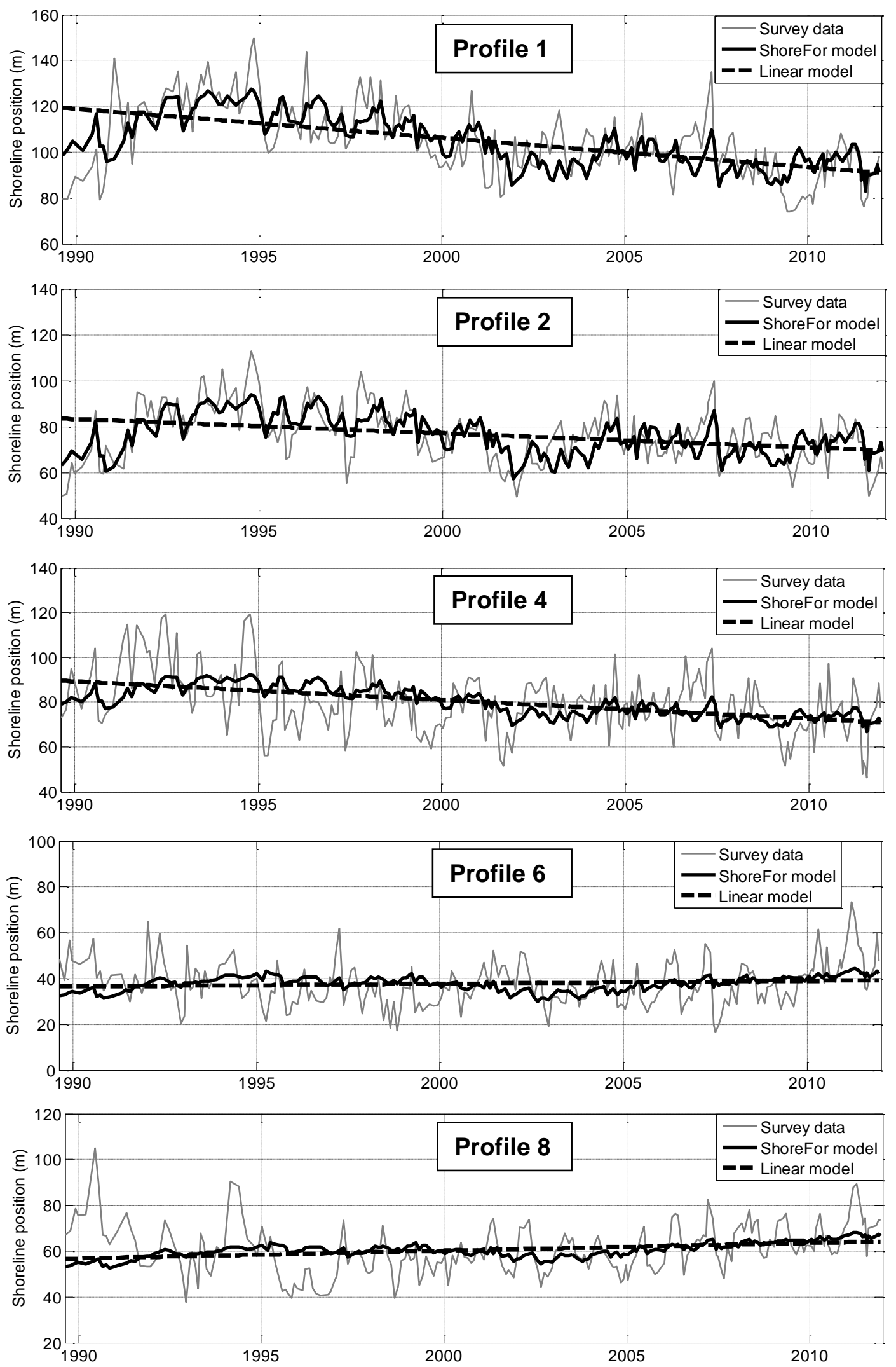

Figure 3. ShoreFor model application to 22 years of monthly surveyed shoreline data $(5$ profiles, 228 surveys) from the Narrabeen site. The model is driven with offshore wave data and calibrated to the entire record at each location. 
While annual cycles are captured by the model at the southern profiles 6 and 8 (particularly from 2002 to 2008 as shown in Fig. 3), which are more sheltered from the predominant south-south-east wave direction, the large amplitude multi-year accretion/erosion cycles are out of phase with the low frequency variability in the dimensionless fall velocity timeseries (see Fig. 4). At Profile 1, the multiyear shoreline displacement is generally inverse to the multi-year variability in the dimensionless fall velocity timeseries (especially from 1987 to 1995). This inverse behaviour is essential for model performance, as the cross-shore model assumes that increasing dimensionless fall velocity causes erosion and decreasing dimensionless fall velocity causes accretion. As this pattern is absent in the multi-year shoreline variability at the southern end of the embayment (e.g. Profile 8), the model is not able to replicate the large lower-frequency signals, so the prediction converges toward the linear trend.
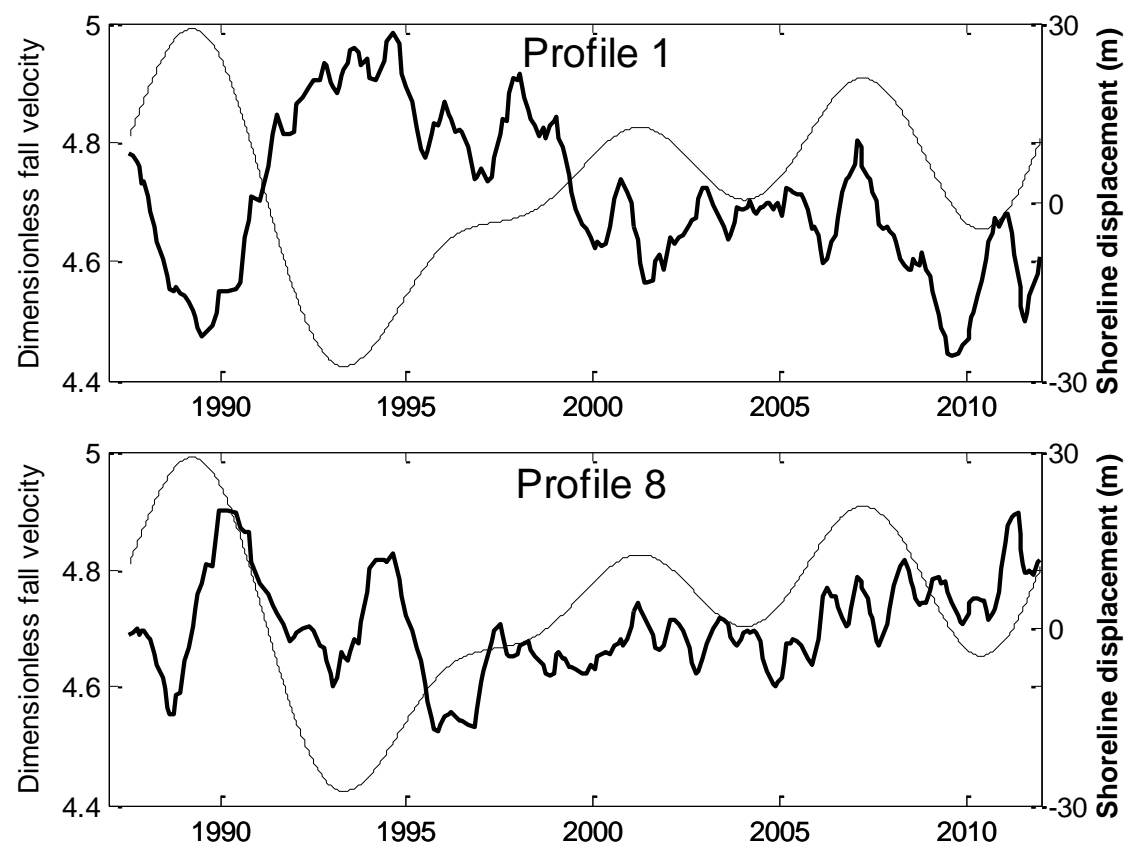

Figure 4. Low pass filtered (cut off period of 5 years) dimensionless fall velocity timeseries and shoreline timeseries from the northern Profile 1 and southern Profile 8 , smoothed as running mean of $+/-3$ months.

Based on the reduced skill of ShoreFor at the sheltered southern profiles when driven with the offshore wave data, a SWAN model of the embayment was used to calculate nearshore timeseries at 10 $\mathrm{m}$ water depth to investigate what improvement could be achieved with more appropriate localised wave data. By necessity, the simulation length was reduced from the 22 years described above to the 18 years when directional wave data is available at the study site, including the two year lead time required to adequately characterize the antecedent conditions. A summary of model coefficients and performance indicators when driven with both the offshore timeseries and the transformed nearshore timeseries for all five profiles are summarised in Table 3. In some cases model skill approaches $60 \%$, the amount of shoreline variability attributed to cross-shore sediment transport (Harley et al., 2011b).

The optimized "memory decay" $(\phi)$ values are still around 6 months at the northern profiles and around a week to a month at the southern profiles. Again the accretion and erosion rates vary between profiles, but maintain the approximate c+ to c- ratio of 2:1. In contrast to the model results for the 19892011 simulations (Table 2), the coefficients for the 1994-2011 simulations (Table 3) are more consistent from north to south. When forced with the offshore wave data, the model improvement (indicated by increased $\mathrm{R}^{2}$ values) at the southern profiles is in part due to the exclusion of the early years, where the multi-year shoreline variability does not correspond to the large changes in dimensionless fall velocity (as shown in Fig. 4). The use of transformed nearshore data rather than the offshore data resulted in a small improvement at all profiles, but did not correct for the large discrepancies still observed at the southern, more sheltered profiles. The improved model predictions at the central (profile 4) and southern profiles (profiles 6 and 8) over this shorter simulation length, when driven with both offshore and nearshore data are shown in Figure 5. 
Table 3. ShoreFor model coefficients and performance indicators at five profiles over period $1994-2011$ (190 surveys), driven with offshore and transformed nearshore wave data.

\begin{tabular}{|c|c|c|c|c|c|c|c|c|c|c|}
\hline $\begin{array}{l}\frac{0}{\square} \\
\frac{0}{0}\end{array}$ & Wave data & $\begin{array}{l}\Phi \\
\text { (days) }\end{array}$ & $\begin{array}{l}\mathrm{b} \\
(\mathrm{m} / \mathrm{yr})\end{array}$ & $\begin{array}{l}\mathrm{C+} \\
\left(\times 10^{-8}\right. \\
(\mathrm{m} / \mathrm{s})^{*} \\
\left.(\mathrm{~W} / \mathrm{m})^{-0.5}\right)\end{array}$ & $\begin{array}{l}\text { Ratio } \\
\text { of } C_{+} \\
\text {to c- }\end{array}$ & $\begin{array}{l}\mathrm{R}^{2} \\
\text { linear } \\
\text { model }\end{array}$ & $\begin{array}{l}\mathrm{R}^{2} \\
\text { Shore- } \\
\text { For } \\
\text { model }\end{array}$ & $\begin{array}{l}\text { RMSE } \\
\text { linear } \\
\text { model } \\
(\mathrm{m})\end{array}$ & $\begin{array}{l}\text { RMSE } \\
\text { ShoreFor } \\
\text { model (m) }\end{array}$ & BSS \\
\hline \multirow[t]{2}{*}{1} & Offshore & 180 & -1.71 & 2.64 & 2.18 & 0.38 & 0.50 & 11.0 & 10.0 & 0.36 \\
\hline & Nearshore & 240 & -1.73 & 5.00 & 2.25 & 0.38 & 0.55 & 11.0 & 9.4 & 0.44 \\
\hline \multirow[t]{2}{*}{2} & Offshore & 160 & -0.94 & 3.16 & 2.19 & 0.17 & 0.41 & 10.2 & 8.6 & 0.47 \\
\hline & Nearshore & 140 & -0.96 & 7.14 & 2.16 & 0.17 & 0.41 & 10.2 & 8.6 & 0.47 \\
\hline \multirow[t]{2}{*}{4} & Offshore & 180 & -0.59 & 2.35 & 2.18 & 0.05 & 0.17 & 12.1 & 11.4 & 0.30 \\
\hline & Nearshore & 180 & -0.62 & 5.07 & 2.35 & 0.05 & 0.26 & 12.1 & 10.9 & 0.36 \\
\hline \multirow[t]{2}{*}{6} & Offshore & 45 & 0.57 & 2.63 & 2.14 & 0.09 & 0.27 & 9.1 & 8.2 & 0.39 \\
\hline & Nearshore & 40 & 0.55 & 7.75 & 2.36 & 0.09 & 0.32 & 9.1 & 8.0 & 0.44 \\
\hline \multirow[t]{2}{*}{8} & Offshore & 5 & 0.95 & 3.58 & 1.66 & 0.24 & 0.37 & 8.8 & 8.0 & 0.39 \\
\hline & Nearshore & 10 & 0.94 & 12.54 & 2.08 & 0.24 & 0.41 & 8.8 & 7.8 & 0.42 \\
\hline
\end{tabular}

Note: in the transformation from offshore to nearshore, wave heights reduce and periods are unchanged or reduced only slightly, so the wave steepness and power both decrease and the coefficients (c+ and c-) must be larger to compensate for these changes.
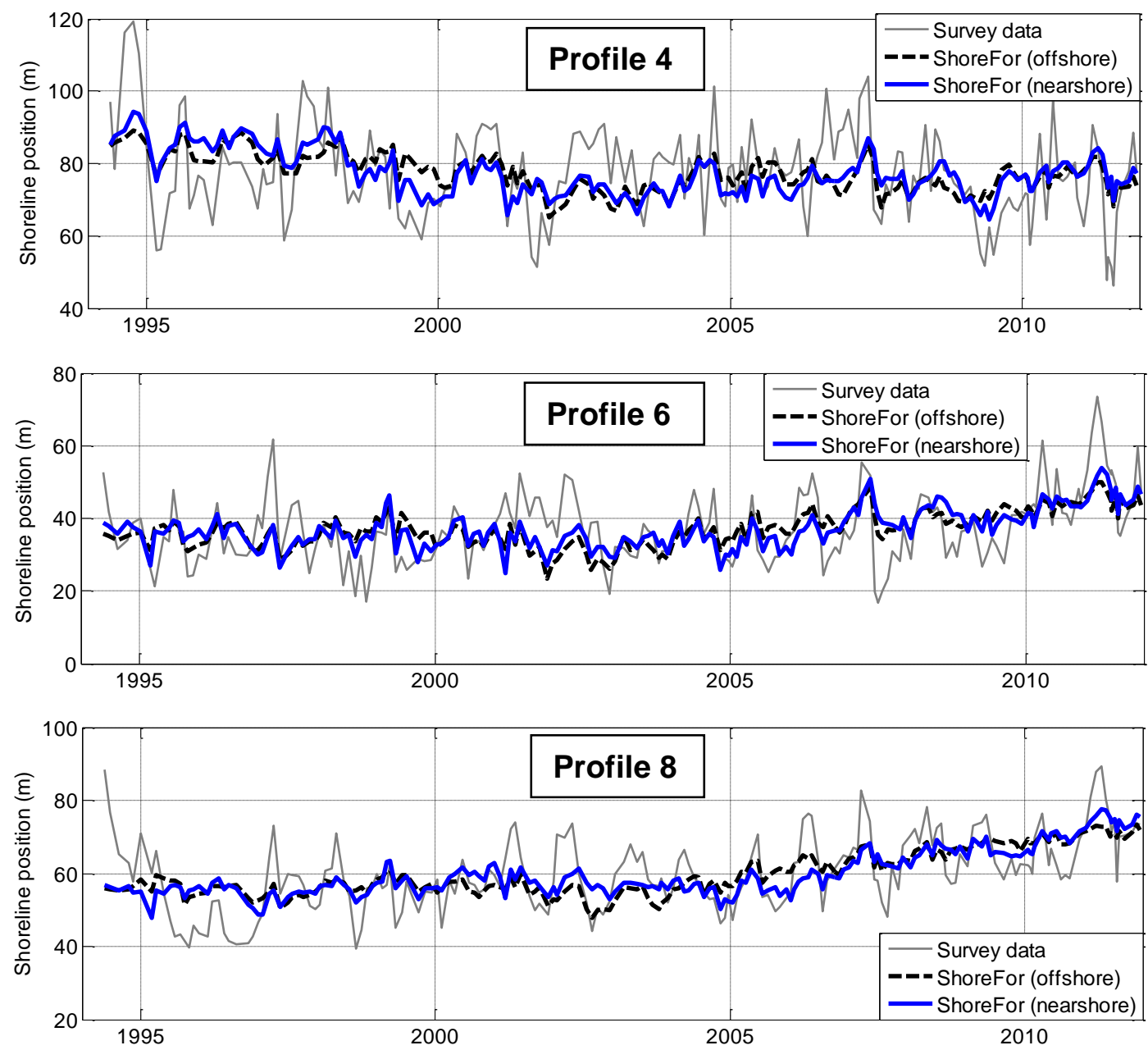

Figure 5. ShoreFor model application to 18 years of monthly surveyed shoreline data (3 profiles, 190 surveys) from the Narrabeen site. The model is calibrated to the entire record at each location and results are shown when it is driven with offshore and transformed nearshore data.

When ShoreFor is instead run only on the last 10 years of the record (2002-2011), where the multiyear variability can be approximated by the linear trend term, the model is more successful at the southern profiles as it captures the annual accretion-erosion cycles as shown for example at Profile 8 in Figure 6. Here the offshore wave data is again used due to its longer record length (and minimal improvement observed when the inshore wave data is used) and its likely broader availability for sites without detailed nearshore wave modelling. 


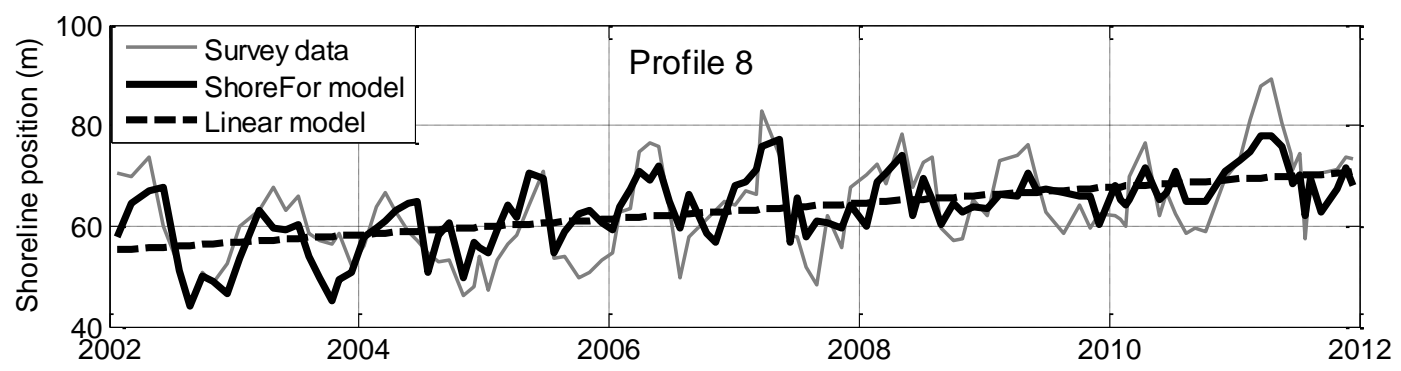

Figure 6. ShoreFor model applied to 10 years of monthly surveyed shoreline data at the southern Profile 8 , driven with offshore wave data, annual cycles are evident.

\begin{tabular}{|c|c|c|c|c|c|c|c|c|c|}
\hline$\frac{\frac{1}{\square}}{\frac{0}{2}}$ & $\begin{array}{l}\Phi \\
\text { (days) }\end{array}$ & $\begin{array}{l}\mathrm{b} \\
(\mathrm{m} / \mathrm{yr})\end{array}$ & $\begin{array}{l}\mathrm{C}+ \\
\left(\mathrm{x} 10^{-8}\right. \\
(\mathrm{m} / \mathrm{s})^{\star} \\
\left.(\mathrm{W} / \mathrm{m})^{-0.5}\right)\end{array}$ & $\begin{array}{l}\text { Ratio } \\
\text { of } \mathrm{C}+ \\
\text { to } \mathrm{C}^{-}\end{array}$ & $\begin{array}{l}\mathrm{R}^{2} \\
\text { linear } \\
\text { model }\end{array}$ & $\begin{array}{l}\mathrm{R}^{2} \\
\text { ShoreFor } \\
\text { model }\end{array}$ & $\begin{array}{l}\text { RMSE } \\
\text { linear } \\
\text { model } \\
(\mathrm{m})\end{array}$ & $\begin{array}{l}\text { RMSE } \\
\text { ShoreFor } \\
\text { model } \\
(\mathrm{m})\end{array}$ & BSS \\
\hline 8 & 10 & 1.53 & 7.42 & 1.85 & 0.24 & 0.60 & 8.0 & 5.8 & 0.67 \\
\hline
\end{tabular}

\section{CONCLUSIONS AND FUTURE WORK}

In order to tackle the multiple challenges of uncertain future climate and the potential impacts to sandy coasts, the first step is being able to reproduce observed long-term (several decades) behaviour with known forcing. In this work, the newly developed ShoreFor empirical shoreline model has been tested with the unique long-term (multi-decadal), high resolution (monthly) survey dataset including five alongshore locations within the Narrabeen-Collaroy embayment in south east Australia. The model was first tested with the available offshore wave data and calibrated to each profile to examine the model performance. In particular, the variation in accretion/erosion response rates along the embayment from the more exposed northern end to the more sheltered southern end decreased with wave exposure. At all locations it was shown to provide an improvement over the widely adopted technique of a linear trend fit through long term data, with seasonal to non-cyclic multi-year accretion-erosion cycles represented. However, this improvement was minimal at the sheltered southern end of the embayment. The offshore wave data was then transformed to appropriate nearshore timeseries with a SWAN model to determine if errors in wave climate contributed to the decrease in model skill, however only marginal improvement in model fit was achieved, indicating that other processes (such as longshore transport) likely dominate the southern end of the embayment (e.g. Harley et al., 2011b).

The model was successfully applied at the southern profiles for simulation lengths of up to 10 years, where the decadal-scale shoreline variability was approximately linear. Based on these findings, it appears that the multi-year variability observed in the shoreline dataset must be characterised in a different way. In previous work it has been attributed either wholly or partially to alongshore sediment transport and further ShoreFor model development is in progress aimed at incorporating these processes. The observed multi-year accretion events could also be influenced by lagged cross-shore sediment transport from beyond the surf zone (e.g. Short, 1985; Cowell et al., 2000) and further investigation of the local sediment supply must be completed to assess this possibility. Detailed analysis is also underway of the data requirements of this modelling approach to inform further monitoring efforts in regards to how frequently and over what length of time shoreline data must be collected to characterise a sandy beach system.

Work is presently underway to further investigate the factors influencing the multi-year shoreline variability at the sheltered profiles and how these might be incorporated into the model. Model validation will then be performed utilizing both seen and unseen shoreline data and synthetic wave timeseries (e.g. Davidson et al., 2010). It is anticipated that this ongoing work will assist to inform further understanding of the distinct and spatially variable behaviour observed at this site; and to explore the challenges associated with model application at a range of different sites. The next step will be to drive the model with potential future wave and water level scenarios and examine the range of likely shoreline responses. This work has implications for coastal zone management as it may identify any "tipping points" where a systematic change is observed due to increasing water levels and/or changes in wave characteristics. 


\section{ACKNOWLEDGMENTS}

This work would not be possible without the tireless monitoring efforts at Narrabeen-Collaroy by many individuals. The research reported here is being conducted within the Australian Research Council Linkage Project LP100200348, led by Associate Professor Ian Turner of the University of New South Wales (UNSW), in conjunction with: the University of Plymouth; Macquarie University; Warringah Council; Gosford City Council; NSW Office of Environment and Heritage (OEH); and CoastalCOMS. Wave data was provided by the Manly Hydraulics Laboratory on behalf of NSW OEH. M. Mole is funded by the UNSW Faculty of Engineering, Women in Engineering Research Scholarship.

\section{REFERENCES}

Cowell, P.J, M.J.F. Stive, P.S. Roy, G.M. Kaminsky, M.C. Buijsman, B.G. Thom and L.D. Wright, 2001. Shoreface sand supply to beaches, in Proceedings of the $27^{\text {th }}$ International Conference on Coastal Engineering, ASCE, New York, USA, 2495-2508.

Davidson, M.A., R.P. Lewis and I.L. Turner, 2010. Forecasting seasonal to multi-year shoreline change, Coastal Engineering, 57, 620-629.

Davidson, M.A., K.D. Splinter and I.L. Turner (submitted). A simple equilibrium model for predicting shoreline change, submitted to Coastal Engineering.

Dean, R.G., 1973. Heuristic models of sand transport in the surfzone, Proceedings of the $1^{\text {st }}$ Australian Conference on Coastal Engineering, 209-214.

Gourlay, M.R., 1968. Beach and dune erosion tests, Delft Hydraulics Laboratory Report m935/m936, Delft, The Netherlands.

Harley, M.D., I.L. Turner, A.D. Short and R. Ranasinghe, 2011a. Assessment and integration of conventional, RTK-GPS and image-derived beach survey methods for daily to decadal coastal monitoring, Coastal Engineering, 58, 194-205.

Harley, M.D., I.L. Turner, A.D. Short and R. Ranasinghe, 2011b. A re-evaluation of coastal embayment rotation: the dominance of cross-shore versus alongshore sediment transport processes in SE Australia, Journal of Geophysical Research, 116, F04033, doi:10.1029/2011JF001989.

Miller, J.K. and R.G. Dean, 2004. A simple new shoreline change model, Coastal Engineering, 51, 531-556.

Mole, M.A., M.A. Davidson, I.L. Turner and I.D. Goodwin, 2011. Modelling seasonal to multi-year shoreline change at a sandy embayment on the Australian east coast, in Proceedings of Coasts and Ports 2011, Engineers Australia, Perth.

Short, A.D., 1985. Rip current type, spacing and persistence, Narrabeen Beach, Australia, Marine Geology, 65, 47-71.

Sutherland, J., A.H. Peet and R.L. Soulsby, 2004. Evaluating the performance of morphological models, Coastal Engineering, 51, 917-939.

Wright, L.D., A.D. Short and M.O. Green, 1985. Short-term changes in the morphodynamic states of beaches and surf zones; an empirical predictive model, Marine Geology, 62, 339-364.

Yates, M.L., R.T. Guza and W.C. O’Reilly, 2009. Equilibrium shoreline response: observations and modeling, Journal of Geophysical Research, 114, C09014, 16pp. 